Bei den Nachrichten im öffentlich-rechtlichen Fernsehen dagegen steigt die Zuschauerzahl wieder. Nach dem Regierungswechsel hatten viele Polen das Programm boykottiert. Im Oktober schalteten aber wieder 4,3 Millionen ein - 1,5 Millionen mehr als im September. „Die Propaganda wirkt“, interpretiert Redakteur Michał Kokot die Zahlen. „Die Menschen wissen nicht mehr, was Tatsache und was Meinung ist. Denn alle Medien beteiligen sich am Meinungskampf." Die Situation beim öffentlichen Rundfunk verbessern könne nur eine radikale Abkoppelung von der Politik, meint die ehemalige Fernsehjournalistin Monika Sieradzka „Aber welche Regierung wird daran schon Interesse haben?", fragt sie. Ihr deutscher Kollege Gerhard Gnauck ist optimistischer. Er schaltet öfter den privaten Info-Kanal TVN ein. Dorthin seien viele Kollegen aus dem öffentlichen Fernsehen gewechselt. „Ich setze auf den Pluralismus der polnischen Medien“, sagt er.

\section{Abschied von der türkischen Pressefreiheit Von Kristina Karasu (Türkei)}

Seit in der Türkei im Juli der Ausnahmezustand ausgerufen wurde, existiert Pressfreiheit nur noch auf dem Papier. Über 120 einheimische Journalisten und Medienschaffende wurden seither festgenommen, über 170 Medien ließ die Regierung schließen. Berichterstattung aus diesem Land gleicht einem Drahtseilakt.

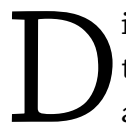
ie älteste türkische Tageszeitung „Cumhuriyet“, Preisträger des diesjährigen Alternativen Nobelpreises, gilt als eine der letzten Festungen oppositioneller Berichterstattung, doch auch sie steht derzeit unter Beschuss. Am 31. Oktober wurde ihr Chefredakteur Murat Sabuncu zusammen mit zwölf weiteren Mitarbeitern der Zeitung festgenommen. Der ehemalige Chefredakteur Can Dündar wurde bereits im Mai nach der Veröffentlichung eines Artikels über angebliche türkische Waffenlieferungen an Islamisten in Syrien zu einer mehrjährigen Haftstrafe verurteilt. Er konnte die Türkei im Juli verlassen und lebt seitdem im deutschen Exil. Den Journalisten wird Unterstützung der kurdischen Miliz PKK sowie der islamischen Gülen-Bewegung vorgeworfen. Dabei schrieben viele der jetzt Festgenommenen seit Jahrzehnten gegen PKK und Gülen-Bewegung, gegen Putschversuche und Terror an. Doch seit in der Türkei der Ausnahmezustand regiert, sind

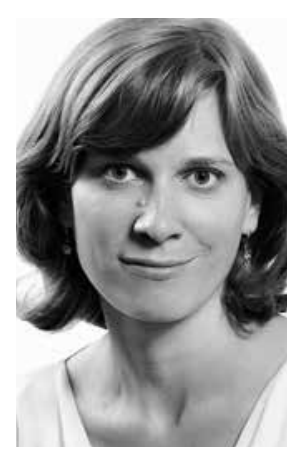

Kristina Karasu arbeitet als freie Journalistin und Filmemacherin in Istanbul und Essen. Sie ist Türkei-

Korrespondentin der Presseschau „eurotopics", zu ihren Auftraggebern gehören außerdem Deutsche Welle TV, ZDF, ARTE, WDR5 und "Vorwärts". 
Tatsachen nebensächlich. Der grausame Putschversuch vom 15. Juli rechtfertigte für viele Türken zunächst ein hartes Vorgehen. Über 240 Menschen starben dabei, Wut und Trauer regierten das Land. Die Regierung machte schnell die Gemeinde des im US-Exil lebenden Predigers Fethullah Gülen für den Putschversuch verantwortlich und verhängte wenige Tage später den Ausnahmezustand, angeblich um besser gegen die Bewegung vorzugehen. Die hatte seit Jahrzehnten den türkische Justizund Sicherheitsapparat unterwandert, war allerdings lange enger Verbündeter der amtierenden AKP-Regierung, bis es wohl im Jahr 2013 zum Bruch zwischen Gülen und Recep Tayyip Erdoğan kam.

So richteten sich die juristischen Maßnahmen des Ausnahmezustandes tatsächlich zunächst nur gegen mutmaßliche Anhänger, Medien, Schulen und Firmen der Gülen-Bewegung - schon damals in ausuferndem, wenig

Über 170 Medien und Verlage

ließ die türkische Regierung schließen, darunter vor allem kurdische, aber auch linke Medien. rechtsstaatlichem Maße. Doch dabei blieb es nicht. In den folgenden Wochen wurden über 120 Medienschaffende festgenommen, darunter landesweit bekannte Journalisten und Schriftsteller unterschiedlichster politischer Gesinnung. Über 170 Medien und Verlage ließ die Regierung schließen, darunter vor allem kurdische, aber auch linke Medien. $\mathrm{Zu}$ ihnen gehörte auch der kleine sozialistische Fernseh- und Radiosender „Hayatın Sesi“ mit Sitz in Istanbul. Er verstand sich als Bürgersender, der auch Minderheiten und Randgruppen eine Stimme geben wollte. Am 1. Oktober wurde juristisch seine Schließung angeordnet und seine komplette Einrichtung und Technik beschlagnahmt. Vorgeworfen wird ihm Unterstützung der verbotenen kurdischen Arbeiterpartei PKK. Absurd, erklärt Programmkoordinator Arif Koşar: „Wir haben nie Terror oder Gewalt unterstützt und etwa die Terroranschläge der letzten Monate aufs Schärfste verurteilt. Aber darum geht es hier gar nicht. Wer es wagt, noch irgendetwas gegen die Regierung zu sagen, wird zum Terroristen erklärt.“ Die Entscheidung sei für ihn daher kaum überraschend gewesen, sondern das Resultat monatelangen politischen und wirtschaftlichen Drucks. „Uns wurden zahlreiche Geldstrafen auferlegt und unsere Werbekunden zogen sich aus Angst, selber unter Druck zu geraten, zurück. Der Ausnahmezustand ist nur der Gipfel dieser Entwicklung. Die Regierung nutzte ihn nun aus, um uns und andere kritische Medien zu schließen." Eine Chance auf Verteidigung habe „Hayatın Sesi“ nicht gehabt - weder habe es 
ordentliche Ermittlungen noch ein Gerichtsverfahren gegeben. Fassungslos und erstarrt blicken kritische Geister auf diese Entwicklung. Während es vor ein paar Jahren noch eine lebendige türkische Medienszene mit den unterschiedlichsten Stimmen gab, sind mittlerweile fast alle Sender und Zeitungen auf Regierungslinie. Nationalistische Rhetorik bestimmt spätestens seit dem Sommer die Politik, und die meisten türkischen Medien ziehen mit. Laut dem Index für Pressefreiheit von „Reporter ohne Grenzen“ liegt die Türkei auf dem 151. Platz von 180 Ländern. Im Jahr 2008 rangierte sie noch auf dem 102. Platz.

Das hat nicht nur politische, sondern auch wirtschaftliche Gründe. Die meisten Medien gehören großen Mischkonzernen, die auch in branchenfernen Sektoren wie Energie, Bau oder Finanzen tätig sind. Um an lukrative Staatsaufträge zu gelangen, vermeiden sie oppositionelle Berichterstattung, die die Regierung erzürnen könnte. Gleichzeitig unterschlagen sie kritische Informationen über eigene Großprojekte. Verlegerische Unabhängigkeit genießen nur die wenigsten, meist kleinen Zeitungen wie die „Cumhuriyet“. Gleichzeitig kaufen seit 2010 vermehrt islamisch-konservative Unternehmer auf Geheiß der Regierung große Medien auf.

Journalist_innen berichten so, wie sie glauben, dass es der Regierung gefällt aus Angst, als Landesverräter oder Terrorist beschimpft zu werden. Die Regierungsmeinung nimmt in den Medien dementsprechend überproportional großen Raum ein. Nicht selten übertragen dutzende TV-Sender gleichzeitig live eine Rede des Präsidenten oder Premierministers.

Türkische Journalist_innen großer Tageszeitungen, die lieber anonym bleiben wollen, klagen über grassierende Selbstzensur in ihren Redaktionen. „Ein Anruf aus Ankara ist gar nicht mehr nötig, die Redakteure berichten schon von alleine so, wie sie glauben dass es der Regierung gefällt." Sie täten das aus Angst, ihren Job zu verlieren, als Landesverräter oder Terrorist beschimpft zu werden oder gar ins Gefängnis zu müssen. Während des Ausnahmezustands wurde die Untersuchungshaft auf bis zu 30 Tage verlängert, dabei wird den Gefangenen nur selten erlaubt, ihre Anwälte zu sehen. Und schon die Anklageschrift eines Staatsanwaltes genügt, um Menschen bis zu fünf Jahre in Haft zu lassen, bevor ihr Prozess überhaupt beginnt. Überfüllte Gefängnisse und der massive Umbau des Justizsystems lassen jede Hoffnung auf schnelle und faire Prozesse schwinden. Diese Angst und Ungewissheit ersticken bewusst jeden journalistischen Mut. 
Diesen Druck spüren auch ausländische Journalist_innen, die aus der Türkei berichten. Im letzten Jahr wurden sie von regierungsnahen Medien gern zur Zielscheibe erklärt. Insbesondere seit dem Putschversuch werfen sie westlichen Medien mangelnde Empathie und eine imperialistische Agenda vor. Sie würden negativ über die Türkei berichten, um das aufstrebende Land zu schwächen, so die ständig wiederholte Meinung. Manchen westlichen Medien mangelte es tatsächlich an Aufmerksamkeit für die Opfer des Putschversuches, doch die Missstände, die sie anprangern, sind leider

Reporter_innen, insbesondere

Kamerateams, werden immer häufiger von der Polizei kontrolliert und an ihrer Arbeit gehindert. traurige Realität. Die Sensationslust einiger deutscher Medien, die Böhmermann-Krise und die Armenien-Resolution des Bundestages verschärften diese Spannungen in den letzten Monaten weiter. So wollen uns nur noch wenige Türk_innen Interviews geben: Entweder weil sie ausländischen Medien misstrauen oder weil sie Repressalien ihrer eigenen Regierung fürchten. Als TV-Reporterin erlebte ich, wie eine junge Interviewpartnerin, die uns vor der Kamera über ihre persönlichen Ängste und Auswanderungspläne erzählte, später in regierungsnahen Medien und sozialen Netzwerken scharf attackiert wurde.

Reporter_innen, insbesondere Kamerateams, werden immer häufiger von der Polizei kontrolliert und an ihrer Arbeit gehindert. Vor allem wer aus den umkämpften Kurdengebieten im Südosten des Landes berichten will, muss mit Festnahmen oder Beschlagnahmung des Videomaterials rechnen. Dementsprechend reisen nur noch die wenigsten Journalist_innen in die Kurdenregion. So weiß kaum noch jemand, was dort tatsächlich vor sich geht. Doch ohne geprüfte Informationen und ungehinderte Recherchen ist eine faire, ausgewogene Berichterstattung kaum möglich. In dieser Lange ist die desinformierte türkische Bevölkerung der größte Verlierer. Nicht nur die Meinungsfreiheit steht auf dem Spiel, sondern langfristig auch der soziale Frieden des Landes. 